\title{
NOTES
}

\section{Preparation and Properties of Disiloxane-Containing Polyamides from 1,3-Bis(3-aminopropyl)tetramethyldisiloxane and Aromatic Dicarboxylic Acids}

\author{
Yoshiyuki OISHI, Shoichi NAKATA, Mikio KaJIYAMA,* \\ Masa-aki KAKIMOTO, and Yoshio IMAI ${ }^{\dagger}$ \\ Department of Organic and Polymeric Materials, Tokyo Institute of Technology, \\ Ookayama, Meguro-ku, Tokyo 152, Japan \\ * Department of Forest Products, Faculty of Agriculture, \\ The University of Tokyo, Yayoi, Bunkyo-ku, \\ Tokyo 113, Japan
}

(Received March 10, 1989)

KEY WORDS Disiloxane-Containing Polyamides / Solubility / Thermal Behavior /

A considerable number of disiloxane-containing condensation polymrs such as polyamides, polyimides, and heterocylic polymers has been reported, ${ }^{1-9}$ some of which showed good thermal stability and enhanced solubility in organic solvents. 1,3-Bis(3aminopropyl)tetramethyldisiloxane (BATS), which is a commercially available diamine monomer, was already utilized for the preparation of polyimides ${ }^{2,3,6,9}$ and aliphatic polyamides. $^{7,8}$ The BATS-based polypyromellitimide had a melting temperature of $210^{\circ} \mathrm{C},{ }^{9}$ while the polyamides obtained from aliphatic $\mathrm{C}_{3}-\mathrm{C}_{8}$ dicarboxylic acids had low melting temperatures around $60-120^{\circ} \mathrm{C} .^{7}$ However, to our knowledge, the aliphatic-aromatic polyamides derived from BATS and aromatic dicarboxylic acids have not been reported to date. The purpose of this study is to elucidate the effect of tetramethyldisiloxane linkage on the properties of the disiloxane-containing aliphatic-aromatic polyamides.

\footnotetext{
† To whom correspondence should be addressed.
}

\section{EXPERIMENTAL}

\section{Materials}

1,3-Bis(3-aminopropyl)tetramethyldisiloxane (BATS), supplied by Chisso Corp., was purified by distillation over calcium hydride; bp $120^{\circ} \mathrm{C} / 4.5$ Torr. Isophthaloyl chloride (1a) and terephthaloyl chloride (1b) were obtained commercially and purified by vacuum distillation before use. 4,4'-Oxydi(benzoyl chloride) (1c) was prepared conventionally by reaction of 4,4'-oxydi(benzoic acid) with thionyl chloride. Triethylamine and all the solvents used were purified by distillation.

\section{Polymerization}

Polymer 2a. To a solution of $2.485 \mathrm{~g}(10.0$ $\mathrm{mmol}$ ) of BATS and $3.0 \mathrm{ml}$ of triethylamine in $26 \mathrm{ml}$ of chloroform were added $2.030 \mathrm{~g} \mathrm{(10.0}$ $\mathrm{mmol})$ of solid IPC all at once with stirring at $0{ }^{\circ} \mathrm{C}$. Then the solution was stirred at room temperature for $3 \mathrm{~h}$ under nitrogen. The resulting viscous solution was poured into $500 \mathrm{ml}$ of hexane. The precipitated polymer was col- 
lected and dried. The polymer was purified by dissolution in $20 \mathrm{ml}$ of dimethylformamide (DMF), followed by precipitation with $500 \mathrm{ml}$ of water. The product was then dried at $90^{\circ} \mathrm{C}$ for $24 \mathrm{~h}$ under vacuum. The yield was $3.46 \mathrm{~g}$ $(91 \%)$. The inherent viscosity of the polymer in $\mathrm{N}$-methyl-2-pyrrolidone (NMP) was 0.60 $\mathrm{dl}^{-1}$, measured at a concentration of 0.5 $\mathrm{g} \mathrm{dl}^{-1}$ at $30^{\circ} \mathrm{C}$. The IR spectrum (film) exhibited absorptions at $3350 \mathrm{~cm}^{-1}(\mathrm{~N}-\mathrm{H}), 2900$ $\mathrm{cm}^{-1}\left(\mathrm{CH}_{2}\right), 1650 \mathrm{~cm}^{-1}(\mathrm{C}=\mathrm{O}), 1270 \mathrm{~cm}^{-1}$ $\left(\mathrm{Si}-\mathrm{CH}_{3}\right)$, and $1050 \mathrm{~cm}^{-1}$ (Si-O-Si). Anal. Calcd for $\left(\mathrm{C}_{18} \mathrm{H}_{30} \mathrm{~N}_{2} \mathrm{O}_{3} \mathrm{Si}_{2}\right)_{n}$ : C, $57.10 \% ; \mathrm{H}$, $7.98 \%$; N, $7.40 \%$. Found: C, $57.41 \%$; $7.69 \%$; N $7.30 \%$.

Polymers $\mathbf{2 b}$ and $\mathbf{2 c}$ were prepared by a similar procedure to that described above.

\section{Measurements}

IR spectra were recorded on a JASCO FT/ IR-5000 Fourier transform spectrophotometer. Differential thermal analysis (DTA), differential scanning calorimetry (DSC), and thermogravimetry (TG) were performed with Shimadzu thermal analyzers DTA-30M, DSC41M, TGA-30M, respectively. Wide angle Xray diffraction patterns were obtained for films on a Rigakudenki XG X-ray diffraction apparatus using nickel-filtered $\mathrm{Cu}-K \alpha$ radiation $(30 \mathrm{kV}, 50 \mathrm{~mA})$. Weight-average molecular weight $\left(\bar{M}_{w}\right)$ and number-average molecular weight $\left(\bar{M}_{n}\right)$ were determined by means of a gel permeation chromatography (GPC) on the basis of polystyrene calibration on a JASCO HPLC BIP-1 apparatus (column, Shodex GPC AD-80M/S polystyrene gel; eluent, DMF containing $0.01 \mathrm{moll}^{-1}$ of lithium bromide). Tensile properties were obtained with a Toyo Baldwin Tensilon UTM-III at a strain rate of $20 \% \mathrm{~cm}^{-1}$.

\section{RESULTS AND DISCUSSION}

\section{Polymer Preparation}

The conventional low-temperature solution polycondensation method ${ }^{10}$ was used in the preparation of disiloxane-containing aliphatic-aromatic polyamides $\mathbf{2 a - 2}$ starting from BATS and aromatic diacid chlorides $1 \mathbf{a}-\mathbf{1 c}$ (eq 1). The polymerization was carried out at room temperature in an organic solvent with the use of triethylamine as an acid acceptor.

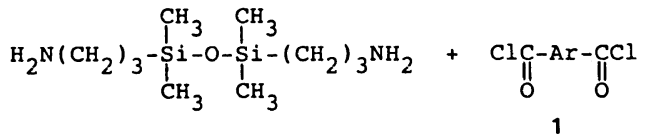

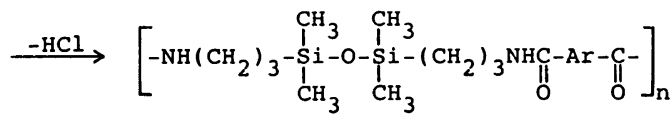

$$
\begin{aligned}
& 2 \\
& \mathrm{Ar}: \mathrm{O}(\mathrm{a}), \mathrm{O}(\mathrm{b}), \mathrm{O}-\mathrm{O} \text { (c) }
\end{aligned}
$$

The effect of reaction medium was first examined on the polycondensation of BATS with 1a, and the results are summarized in Table I. The polymerizations in all the solvents used proceeded readily in homogeneous solution. Among them, chlorinated hydrocarbons such as dichloromethane and chloroform was found to be effective for the preparation of polymer 2a with reasonably high inherent viscosity of over $0.5 \mathrm{dlg}^{-1}$, compared with NMP, a typical amide-type solvent. Other polymers $\mathbf{2 b}$ and $\mathbf{2 c}$ having inherent viscosities of $0.3-$ $0.4 \mathrm{dlg}^{-1}$ were also obtained by the polymerizations in chloroform (Table I). A GPC study indicated that polymer $\mathbf{2 a}$ with inherent viscosity of $0.60 \mathrm{dlg}^{-1}$ corresponded to $\bar{M}_{w}$ and $\bar{M}_{n}$ values of 190000 and 106000 , respectively, relative to standard polystyrene, and the $\bar{M}_{w} / \bar{M}_{n}$ ratio was 1.8 .

The structures of the polymers thus obtained were confirmed to be the proposed disiloxane-containing polyamides by means of IR spectroscopy and elemental analysis.

\section{Polymer Characterization}

The X-ray diffraction study indicated that all the polymers were amorphous. These disiloxane-containing polyamides dissolved readily in a variety of solvents such as DMF, 
Table 1. Preparation of polyamides from BATS and aromatic dicarboxylic acid chlorides ${ }^{a}$

\begin{tabular}{|c|c|c|c|c|}
\hline \multirow{3}{*}{$\begin{array}{l}\text { Diacid } \\
\text { chloride }\end{array}$} & \multirow{3}{*}{$\begin{array}{l}\text { Reaction } \\
\text { medium }\end{array}$} & \multicolumn{3}{|c|}{ Polymer } \\
\hline & & \multirow{2}{*}{ Code } & Yield & $\eta_{\mathrm{inh}}^{\mathrm{b}}$ \\
\hline & & & $\%$ & $\mathrm{dl} \mathrm{g}^{-1}$ \\
\hline 1a & Dichloromethane & 2a & 84 & 0.51 \\
\hline 1a & Chloroform & $2 a$ & 91 & 0.60 \\
\hline $1 \mathbf{a}$ & $\begin{array}{l}N \text {-Methyl-2- } \\
\text { pyrrolidone }\end{array}$ & $2 a$ & 78 & 0.26 \\
\hline 1b & Chloroform & $\mathbf{2 b}$ & 90 & 0.42 \\
\hline 1c & Chloroform & $2 c$ & 95 & 0.32 \\
\hline
\end{tabular}

a Polymerization was carried out with $10 \mathrm{mmol}$ of each monomer and $21 \mathrm{mmol}$ of triethylamine in $26 \mathrm{ml}$ of the solvent at $20^{\circ} \mathrm{C}$ for $3 \mathrm{~h}$.

b Measured at a concentration of $0.5 \mathrm{~g} \mathrm{dl}^{-1}$ in NMP at $30^{\circ} \mathrm{C}$.

NMP, dimethyl sulfoxide, pyridine, tetrahydrofuran, $m$-cresol, and chloroform at room temperature, and even in hot ethanol. They are practically insoluble in hexane. Since aliphaticaromatic polyamides derived from aliphatic diamines and aromatic diacids dissolved only in acidic media such as $m$-cresol and trifluoroacetic acid, ${ }^{11}$ the enhanced solubility characteristics of the disiloxane-based polyamides are probably attributable to the amorphous nature of these polymers due to the existing tetramethyldisiloxane linkage which disturbs the close packing of the polymers.

A colorless, transparent and flexible film of polymer $2 \mathrm{a}$ could be obtained by hot pressing or by casting from the DMF solution. The cast film had a tensile strength of $14 \mathrm{MPa}$, an elongation at break of $23 \%$, and a tensile modulus of $1.1 \mathrm{GPa}$.

The thermal behavior of the polymers was evaluated by means of DTA, DSC, and TG. Figure 1 shows the DTA and TG curves of polymer $\mathbf{2 a}$, and thermal properties are summarized in Table II. None of the polyamides decomposed below $320^{\circ} \mathrm{C}$ in air, and the $10 \%$ weight loss occurred between $420^{\circ} \mathrm{C}$ and $440^{\circ} \mathrm{C}$ in air and nitrogen. These decomposition temperatures are somewhat higher than

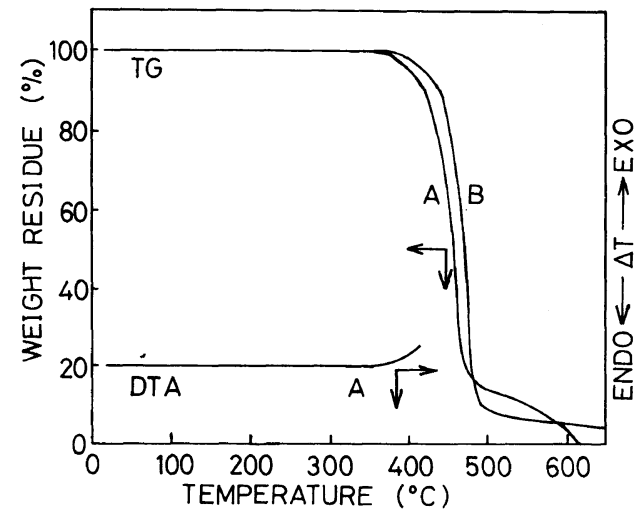

Figure 1. DTA and TG curves of polymer $2 \mathbf{a}$ at a heating rate of $10^{\circ} \mathrm{C} \mathrm{min}^{-1}$ in air (A) and in nitrogen (B).

Table II. Thermal behavior data of polyamides

\begin{tabular}{cccc}
\hline & $\begin{array}{c}\text { Glass transition } \\
\text { Pemperature }\end{array}$ & \multicolumn{2}{c}{$\begin{array}{c}\text { Decomposition } \\
\text { temperature }^{\mathrm{b}}\end{array}$} \\
\cline { 2 - 3 } \cline { 4 - 4 } & C & In air & In nitrogen \\
\cline { 3 - 4 } 2a & 82 & 420 & 440 \\
2b & 90 & 400 & 435 \\
2c & 91 & 425 & 440 \\
\hline
\end{tabular}

a Determined by DSC at a heating rate of $20 \mathrm{C} \mathrm{min}^{-1}$ in nitrogen.

b Temperature at which $10 \%$ weight loss was recorded by TG at a heating rate of $10^{\circ} \mathrm{Cmin}^{-1}$.

those of the polyamides derived from BATS and aliphatic diacids, as well as wholly aliphatic polyamides. $^{7}$

The glass transition temperatures $\left(T_{\mathrm{g}}\right)$ are between 82 and $91^{\circ} \mathrm{C}$ irrespective of the nature of the aromatic moiety introduced in the polymer backbone. Since the polyisophthalamides and polyterephthalamides containing $\mathrm{C}_{6}-\mathrm{C}_{8}$ methylene chains have $T_{\mathrm{g}}$ 's between 105 and $125^{\circ} \mathrm{C},{ }^{11}$ the $T_{\mathrm{g}}$ 's of the disiloxanecontaining aliphatic-aromatic polyamides are quite reasonable, and are about $60^{\circ} \mathrm{C}$ higher than those of the polyamides based on BATS and aliphatic diacids, which are below $20^{\circ} \mathrm{C}$. It is of interest that the $T_{\mathrm{g}}$ 's of the polyamides obtained here are about $10-15^{\circ} \mathrm{C}$ higher than 
those of the polyimides derived from BATS and both 3,3',4,4'-biphenyltetracarboxylic and $3,3^{\prime}, 4,4^{\prime}$-benzophenonetetracarboxylic dianhydrides. ${ }^{9}$ This may be explained by the presence of hydrogen bonding in the polyamides.

\section{REFERENCES}

1. J. E. Mulvaney and C. S. Marvel, J. Polym. Sci., 50, 541 (1961).

2. H. Kuckertz, Makromol. Chem., 98, 101 (1966).

3. G. Greber, J. Prakt. Chem., 313, 461 (1971).

4. J.-C. Bonnet and E. Marechal, Bull. Soc. Chim. Fr., 3561 (1972).

5. L. W. Breed and J. C. Wiley, Jr., J. Polym. Sci.,
Polym. Chem. Ed., 14, 83 (1976).

6. S. Maudgal and T. L. St Clair, Int. J. Adhesion Adhesives, 4, 87 (1984).

7. T. Kiyotsukuri, N. Tsutsumi, K. Ayama, and M. Nagata, J. Polym. Sci., Polym. Chem. Ed., 25, 1591 (1987).

8. T. Kiyotsukuri, N. Tsutsumi, K. Ayama, and M. Nagata, J. Polym. Sci., Polym. Chem. Ed., 26, 807 (1988).

9. N. Tsutsumi, A. Tsuji, C. Horie, and T. Kiyotsukuri, Eur. Polym. J., 24, 837 (1988).

10. P. W. Morgan, "Condensation Polymers by Interfacial and Solution Methods," Interscience, New York, N.Y., 1965.

11. P. W. Morgan and S. L. Kwolek, Macromolecules, 8, 104 (1975). 